\title{
The Application of Hot Water Flow Method for Checking the Water Circuit Within the Winding of Turbo Generator
}

\author{
Ming $\mathrm{Li}^{1, \mathrm{a}}$, Andong Wang ${ }^{1, \mathrm{~b}}$, Zhiwei Cao ${ }^{1, \mathrm{c}}$, Fuchun Sun ${ }^{1, \mathrm{~d}}$, \\ Shanhua Sun ${ }^{1, e}$, Guangke Xu1,f, Weiwei Zhang ${ }^{1, g}$,Changling Wang ${ }^{2, h}$ \\ ${ }^{1}$ State Grid Shangdong Electric Power Research Institute, Jinan, 250002, China \\ 2Shandong Zhongshiyitong Group Co. Ltd, Jinan, 250002, China \\ aliming88419@163.com, bandong_wang@126.com, czw_cao@163.com, d353373462@qq.com,

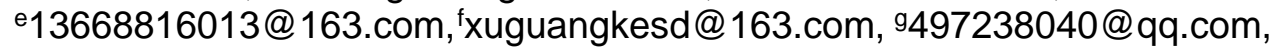 \\ h18560148880@163.com
}

\begin{abstract}
Keywords: hot water flow method, winding of turbo generator, water circuit, flow, temperature Abstract. The hot water flow method, which has been gradually applied, is very useful for Checking the Water Circuit within the Winding of Turbo Generator. Simulation tests are first shown in this paper at the beginning and the factors concerned with the tests are studied such as flow and temperature difference. Then, hot water flow field test is conducted in some power plants. In the end, some conclusions are drawn which will make useful reference and guidance for field test and application.
\end{abstract}

\section{Introduction}

The hot water flow method is very useful for checking the water circuit within the winding of turbo generator when the turbo generator is equipped in the manufacture works and the method has been gradually applied by the engineers in the power plant. The test usually accords to the standard JB/T6228-2005 <Checking methods and evaluation of water circuit within the winding of turbo generator> to check whether the winding of turbo generator has been blocked by impurities. However, this standard can only offer qualitative guidelines for checking those windings that are seriously blocked rather than providing quantitative guidelines for common windings. Therefore, simulation tests are designed in the laboratory, combined with field tests in some power plants. Through Comparison and analysis between those tests, some conclusions such as the test feature and the quantitative judgement are drawn in the end, which is proved in field application and can be of great significance for actual work.

\section{Theory analysis}

Generally, the hot water flow method is divided into three steps, namely, heating the windings of turbo generator, cooling the inner cooling water, cooling the windings.

According to Newton's law of cooling, the dissipation energy per unit time within per unit area is proportional to the temperature difference supposing that the temperature between the object and the surrounding is different, where the proportionality coefficient is named heat transfer coefficient. Specifically, when there is convection between the cold source fluid at the temperature of $\mathrm{T}_{2}$ and the heat source fluid at the temperature of $\mathrm{T}_{1}$, the dissipation energy of fluid $\mathrm{B}$ is shown in equation Eq.1.

$$
Q=c * m *\left(T_{2}-T_{1}\right)=c * \rho * q * t * \Delta T
$$

In Eq.1, $c$ is defined as specific heat capacity, $\rho$ as fluid density, $q$ as fluid flow, $t$ as duration of convection, $\Delta \mathrm{T}$ as temperature difference between the cold source fluid and the heat source fluid.

It can be seen that the dissipation energy of heat source fluid $\mathrm{B}$ is mainly proportional to temperature difference $\Delta \mathrm{T}$ and $\mathrm{q}$, the flow of the cold source fluid. 
According to the classical Fourier law, the amount of heat conducted through per unit cross section per unit time is $\phi$, which is proportional to the temperature gradient perpendicular to the direction of cross section, as shown in Eq.2.

$$
\phi=-\lambda A \frac{\partial t}{\partial x}
$$

In Eq.2, $\lambda$ is defined as thermal conductivity, $\frac{\partial t}{\partial x}$ as temperature gradient. It can easily be drawn that the faster the temperature drops, the more the energy conducted.

As a matter fact, in the hot water flow test, the windings of the generator stator are first heated to some steady temperature by hot water in the water tank, while then be cooled down to another steady temperature by the cold water, and the convection phenomenon is involved in the heating and cooling course. The temperature dropping gradient of the windings of the stator is influenced by heat conductivity coefficient, and is mainly decided by the flow of the fluid (cross section of the water circuit), besides the mechanical and physical parameters of the fluid and the windings. Therefore, the blocking status of the windings can be diagnosed through analyzing the hot water flow test data.

\section{Simulation Tests In Lab}

Introduction. Referring to the basic method requested by the national standard while concerning the needs of field test, a simulation test apparatus is designed to perform simulation tests in the lab. As shown in Fig.1. The simulation test apparatus is mainly composed of one clean stator winding of the $300 \mathrm{MW}$ turbo generator, on cold water tank, one hot water tank, on water pump, one water heater, one water flow meter, two temperature measurement units and the test water loop. The simulation test is performed in the way shown in Fig.1.

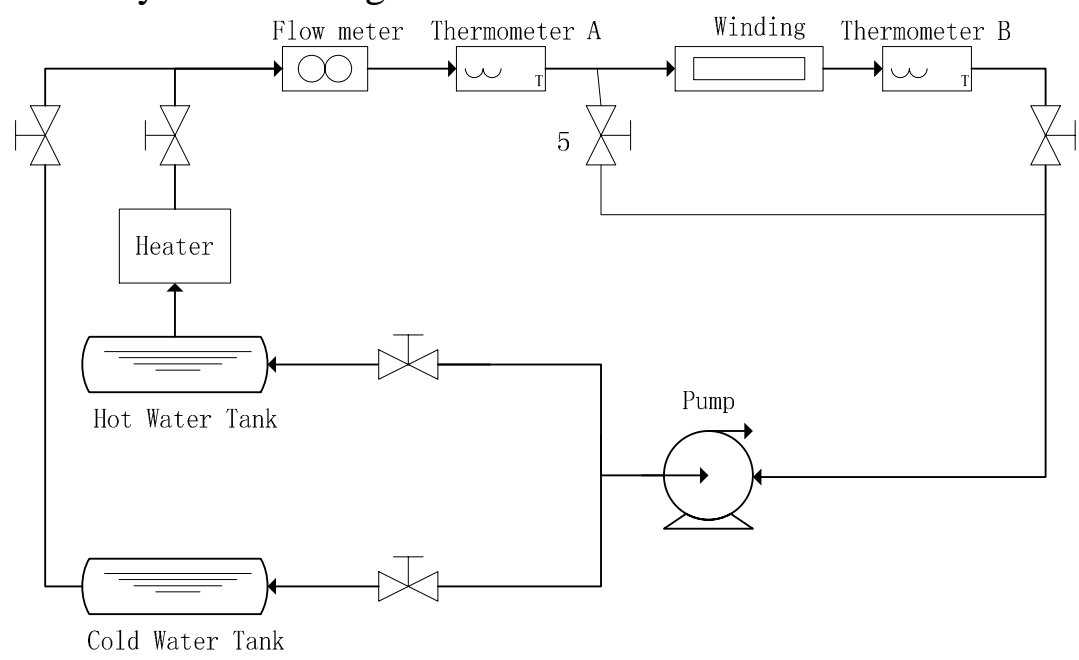

Fig.1. Simulation apparatus of hot water flow test

Firstly, turn on the measurement units concerned with temperature and flow and heat the water tank to some temperature slowly by using the water heater. Secondly, turn on the water pump and the corresponding valves to heat the stator winding with the hot water in the hot water tank until the temperature of the winding is eventually steady and the turn off the pump and the hot water valve. At last, adjust the valve opening to set the water flow and open the hot water pump to cool the winding down with the cold water in the cold water tank until the temperature of the winding no longer drops clearly. The test ends after performing the three steps above.

Simulation tests. Following the steps in the chapter above, some hot water flow simulation tests are performed using the apparatus in the lab through adjusting the water flow and temperature and so on. 
Firstly, the winding is heated to $31^{\circ} \mathrm{C}$ when the cold water is $6{ }^{\circ} \mathrm{C}$, thus , the temperature difference is $25^{\circ} \mathrm{C}$, and conduct the hot water flow test at $100 \%, 90 \%, 80 \%, 70 \%$ of the normal operation flow of the stator winding separately, while keeping the temperature difference the same.

Secondly, change the temperature difference to $20^{\circ} \mathrm{C}, 30^{\circ} \mathrm{C}, 35^{\circ} \mathrm{C}$ separately, and conduct the hot water flow test at $100 \%, 90 \%, 80 \%, 70 \%$ of the normal operation flow of the stator winding separately, corresponding to each temperature difference.

Take the test at the temperature difference of $30{ }^{\circ} \mathrm{C}$ as example, which is shown in Fig.2. The winding is heated to $36^{\circ} \mathrm{C}$ and the cold water is $6{ }^{\circ} \mathrm{C}$. It should be noted that the eventual temperature of the winding is less than $30^{\circ} \mathrm{C}$ higher over the original temperature due to the water loop.

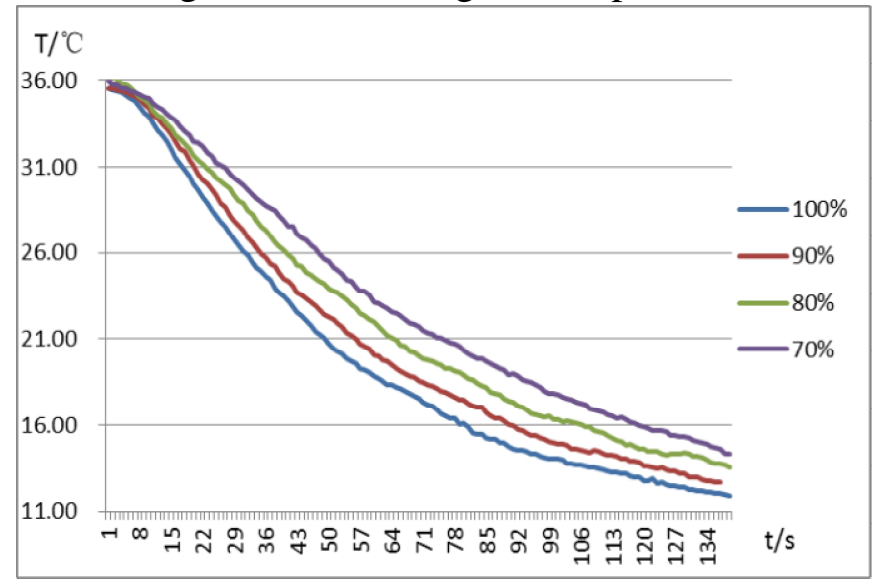

Fig.2. Simulation test at the temperature difference of $30\left[{ }^{\circ} \mathrm{C}\right]$

It can be seen in Fig. 2 that the winding temperature drops faster as the cold water flow increases at the same temperature difference. Specifically, the actual average temperature drop gradient of each flow over the normal flow is shown inTable 1.

TABLE 1 Average temperature drop gradient of each flow over the normal flow

\begin{tabular}{|c|c|c|c|}
\hline Time[s] & $90 \%$ & $80 \%$ & $70 \%$ \\
\hline 30 & $13.16 \%$ & $22.21 \%$ & $36.63 \%$ \\
\hline 45 & $9.83 \%$ & $16.49 \%$ & $31.16 \%$ \\
\hline 60 & $7.30 \%$ & $13.64 \%$ & $23.55 \%$ \\
\hline 75 & $7.18 \%$ & $11.11 \%$ & $21.17 \%$ \\
\hline 90 & $6.44 \%$ & $9.78 \%$ & $18.85 \%$ \\
\hline 105 & $4.38 \%$ & $7.90 \%$ & $14.56 \%$ \\
\hline 120 & $4.72 \%$ & $4.72 \%$ & $11.81 \%$ \\
\hline
\end{tabular}

The hot water simulation test curves of each temperature difference at $100 \%$ normal flow are shown in Fig.3.

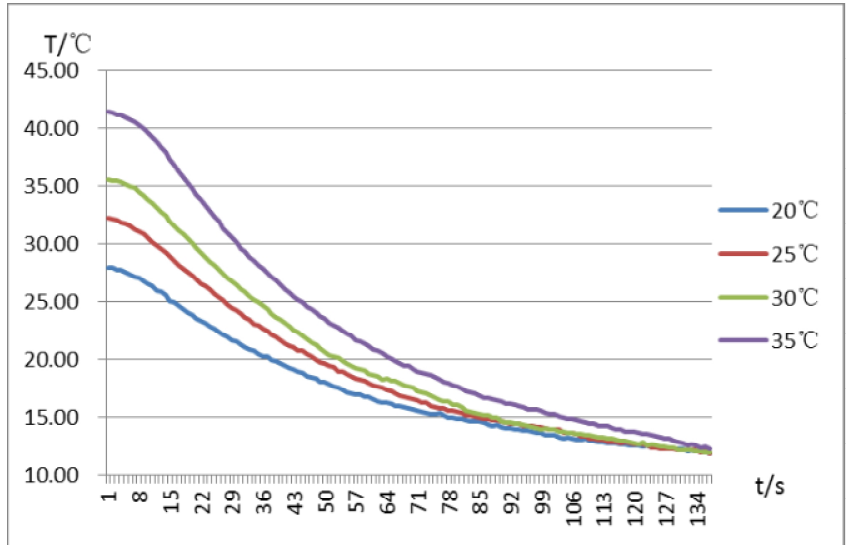

Fig.3. Curves of each temperature difference at $100 \%$ normal flow

It can be seen in Fig. 3 that the winding temperature drops faster as the temperature difference increases at the same water flow. Specifically, the actual average temperature drop gradient of each temperature difference over that of $30^{\circ} \mathrm{C}$ is shown in Table 2. 
TABLE 2 Average temperature drop gradient of each temperature difference over that of $30\left[{ }^{\circ} \mathrm{C}\right]$

\begin{tabular}{|c|c|c|c|}
\hline & $20{ }^{\circ} \mathrm{C}$ & $25{ }^{\circ} \mathrm{C}$ & $35^{\circ} \mathrm{C}$ \\
\hline $30 \mathrm{~s}$ & $-29.47 \%$ & $-12.63 \%$ & $24.42 \%$ \\
\hline 45 & $-31.45 \%$ & $-14.24 \%$ & $21.98 \%$ \\
\hline 60 & $-32.38 \%$ & $-13.94 \%$ & $22.18 \%$ \\
\hline 75 & $-33.54 \%$ & $-13.52 \%$ & $21.59 \%$ \\
\hline 90 & $-33.73 \%$ & $-15.51 \%$ & $20.28 \%$ \\
\hline 105 & $-32.36 \%$ & $-14.92 \%$ & $21.27 \%$ \\
\hline 120 & $-32.31 \%$ & $-14.04 \%$ & $21.25 \%$ \\
\hline
\end{tabular}

Besides, tests above show that the biggest temperature drop gradient of the winding lies at the beginning of the cooling step and the gradient goes down as the test goes on.

\section{FIELD TEST}

At September 2016, the hot water flow field test is executed on \#2 turbo generator of a power plant in Shandong province, China. The \#2 turbo generator is $1000 \mathrm{MW}$, composed of 42 stator windings using inner water cooling system with normal water flow of $120 \mathrm{t} / \mathrm{h}$. The field test includes the following steps.

Firstly, heat the stator winding from $25^{\circ} \mathrm{C}$ high to $47^{\circ} \mathrm{C}$ and the $\mathrm{n}$ adjust the water flow valve to be normal.Secondly, Cool the tank temperature to $22^{\circ} \mathrm{C}$. Thirdly, taking the hot water test at $100 \%$ flow by cooling the stator winding using the cold water.

Reapeating the steps above to take the hot water test at $85 \%$ flow. The seven curves of second lower branch of phase A are shown in Fig.4.

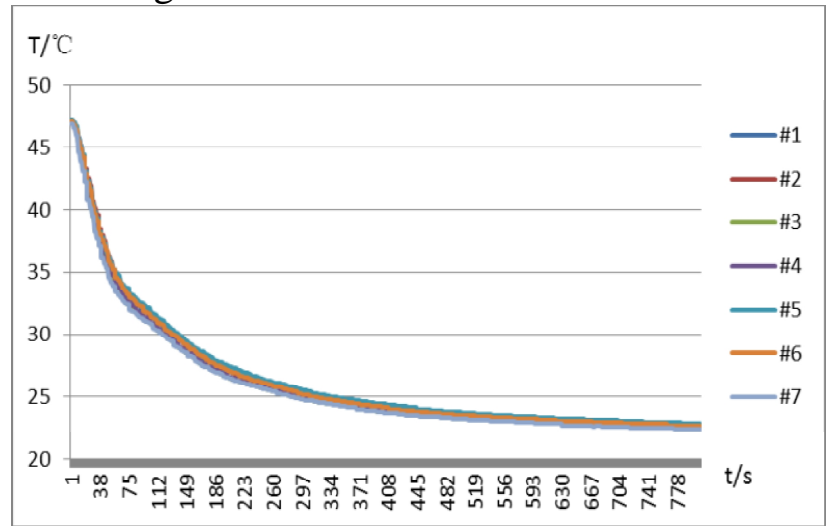

Fig.4. The seven curves of second lower branch of phase A

Fig. 4 shows that the curves of those windings are in good Consistency. The curves of winding \#1 at $100 \%$ and $85 \%$ normal flow are shown in Fig.5.

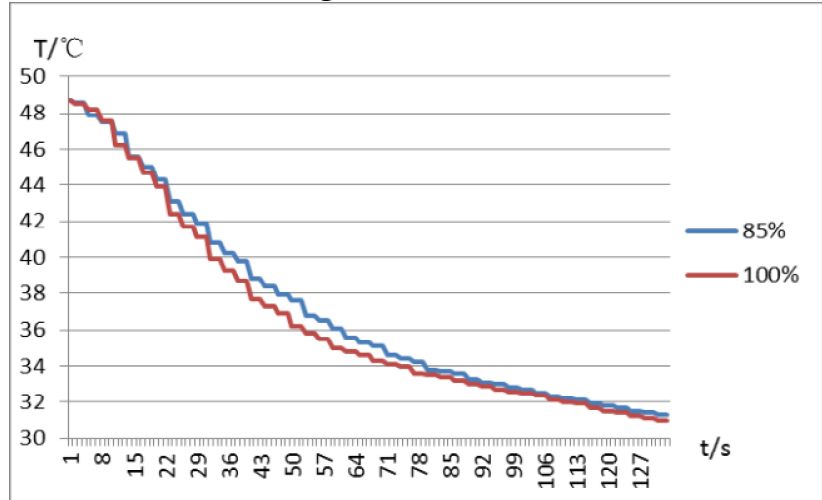

Fig.5. Curves of winding No.28 at $100 \%$ and $85 \%$ normal flow

Through quantitative analysis, the average temperature drop gradient difference of test at $85 \%$ flow over that of $100 \%$ are reached and shown in Table 3. 
TABLE 3 the average temperature drop gradient difference of test at $85 \%$ flow over that of $100 \%$

\begin{tabular}{|c|c|c|c|c|c|c|c|}
\hline $\mathrm{t}(\mathrm{s})$ & 30 & 45 & 60 & 75 & 90 & 105 & 120 \\
\hline $\begin{array}{c}\text { Gradient Differene } \\
(100 \%)\end{array}$ & 10.5 & 9.6 & 8.0 & 2.7 & 1.9 & 0.6 & 1.7 \\
\hline
\end{tabular}

Table 3 proves that in field test the winding out water temperature drops faster with bigger water flow while the average water temperature drop gradient is about $10 \%$ difference between $85 \%$ and $100 \%$ normal flow. As a matter of fact, the flow of each winding in normal operation reflects the water circuit status, which means that small water flow indicates increasing blocking possibility. Thus, by taking hot water flow test, and comparing the out water temperature drop gradient, the blocking status or the severity can be easily judged.

On the other hand, there are some differences between the simulation test and the field test in the power plant, such as that the former one performs on one single stator winding which is very simple while the latter one is actual operation system where the in-water pipe is connected by tens of branches and eventually connected to out-water pipe, all contributing some influences to the test. Thus, the conclusions between the two form of tests have good consistency.

\section{Conclusions}

The hot water flow test of turbo generator is very useful for checking the water circuit of the stator winding and has the following characteristics.

In the test, the out water average temperature gradient is proportional to the flow and the temperature difference.

The average water drop gradient is about $2.5^{\circ} \mathrm{C} / \mathrm{min}$ at the temperature difference $30^{\circ} \mathrm{C}$.

The water circuit can be chekced by comparing the out water temperature drop gradient between the windings.

\section{Acknowledgements}

This work was financially supported by the State Grid Shangdong Electric Power Research Institute Science Foundation (2016-22).

\section{References}

[1] Weiqing Li, Inspectional Analysis and Prevention of Turbo Generator Damage, second ed., China Electric Power Press, Beijing, 2010, pp.126-130 (In Chinese)

[2] DL/T596-1996 <Preventive test code for electric power equipment> (In Chinese)

[3] JB/T6228-2005 <Checking methods and evaluation of water circuit within the winding of turbo generator> (In Chinese) 